\title{
INFLUENCE OF RADIATION AND CONVECTIVE TYPES OF HEAT EXCHANGE ON THE NECESSARY DURATION OF TEMPERATURE MEASUREMENT BY THERMOCOUPLES
}

\author{
Yuliana K. Atroshenko ${ }^{1, *}$, Alena A. Bychkova ${ }^{1}$, and Irina P. Ozerova ${ }^{1}$ \\ ${ }^{1}$ National Research Tomsk Polytechnic University, 634050 Tomsk, Russia
}

\begin{abstract}
Results of research of influence of radiation heat exchange on duration of execution of measurement high темератур are given by thermocouples, influence of the free convection on results of temperature measurement is also considered by the thermocouples set in protective sleeves with a gap. Researches showed that radiation heat exchange leads to lowering of duration of heating of the thermocouple to $30 \%$ whereas the free convection in a protective sleeve practically doesn't exert impact on process of heating up of the sensor.
\end{abstract}

\section{Introduction}

Operation of the equipment on objects of such industries as power engineering, mechanical engineering, metallurgy and others, is often connected to operation in the conditions of high temperatures. Monitoring and control of technological processes on such productions is executed by the automatic systems of monitoring and control executing, first of all, measurements of parameters of processes and the equipment $[1,2]$.

Correct and fastest measurement of parameters of technological process (temperature, pressure, the expenditure, etc.) is a basis of safety, reliability, profitability and overall performance of the equipment $[2,3]$.

It is set $[4,5]$ that the sensor mounting mode on the equipment has significant effect on an inertance of operation of primary transformers of temperature. However, heating up conditions also influence integral characteristics of process of heating.

It is known that with increase in temperature of the controlled environment heattransfer substantially amplifies a radiation component $[6,7]$. This influence is more noticeable in the range of the taken temperatures exceeding $750 \mathrm{~K}$. When reviewing mounting conditions of the sensor in a protective sleeve with filling of the free space with liquid materials influence of possible convection in liquid layers is possible.

\footnotetext{
*Corresponding author: julie55@tpu.ru
} 


\section{Physical model of heat transfer}

In a figure 1, a -the installation diagram of the thermocouple I in a protective sleeve of II with filling of the free space with liquid III is shown. In such conditions influence of the free convection in liquid III layers is possible.

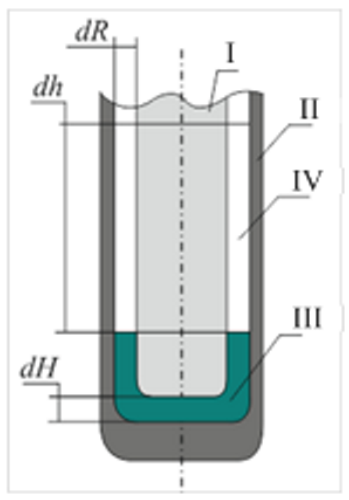

a)

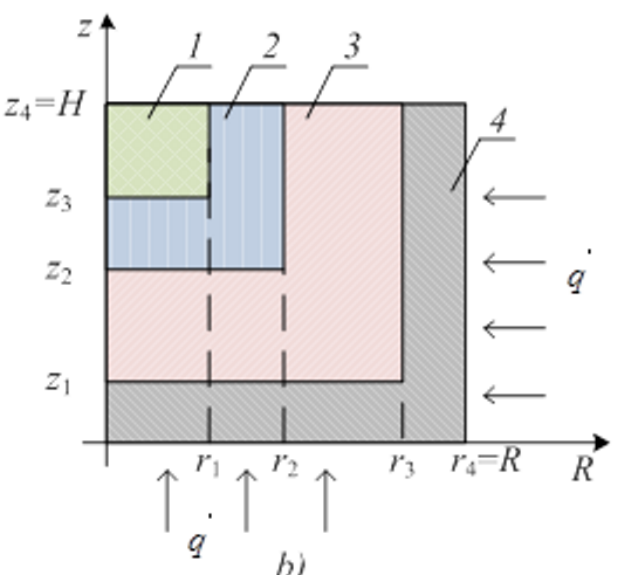

b)

Fig. 1. The installation diagram of the thermocouple in a protective sleeve (a) and the diagram of area of the solution of the task (b): I - the thermocouple, II - a protective sleeve; III - liquid; IV - air; 1 thermocouple junction; 2 - protective cap; 3 - aluminum oxide powder; 3 -protective cover.

In a figure $1, \mathrm{~b}-$ the diagram of area of the solution of the task of heat conduction for a case when on boundaries of area of the decision the heat flux of $q$ is set is shown.

In case of the solution of the task the assumptions which aren't superimposing essential restrictions on a problem definition community are accepted:

1) heatphysical characteristics of elements of area of the decision don't depend on temperature;

2) the sensitive element has the correct cylindrical form.

The initial temperature of the systems shown in a figure 1 makes $20^{\circ} \mathrm{C}$.

The end of process of heating up was defined at the time of achievement by a thermocouple junction of temperature, other than an allowed error measured on value. Permissible deviation [8] for the thermocouple of $\mathrm{K}$ type makes $\pm 1,5$ in the range of temperatures from -40 to $375{ }^{\circ} \mathrm{C} ; \pm 0,004 \cdot \mathrm{t}$ in the range of temperatures from 375 to 1000 ${ }^{\circ} \mathrm{C}$.

For area solutions of the task (fig. $1, b$ ) are made the following sizes: $H=5 \mathrm{~mm} ; R=5$ $\mathrm{mm}$.

\section{Mathematical model and decision methods}

Process of heattransfer in the considered system (fig. 1) is described by system of differential equations:

$$
\begin{aligned}
& c_{1} \rho_{1} \frac{\partial T_{1}}{\partial t}=\lambda_{1}\left(\frac{\partial^{2} T_{1}}{\partial r^{2}}+\frac{1}{r} \frac{\partial T_{1}}{\partial r}+\frac{\partial^{2} T_{1}}{\partial z^{2}}\right), t>0,0<r<r_{1}, z_{3}<z<H ; \\
& c_{2} \rho_{2} \frac{\partial T_{2}}{\partial t}=\lambda_{2}\left(\frac{\partial^{2} T_{2}}{\partial r^{2}}+\frac{1}{r} \frac{\partial T_{2}}{\partial r}+\frac{\partial^{2} T_{2}}{\partial z^{2}}\right), t>0,0<r<r_{2}, z_{2}<z<z_{3} ; r_{1}<r<r_{2}, z_{3}<z<H ;
\end{aligned}
$$




$$
\begin{aligned}
& c_{3} \rho_{3} \frac{\partial T_{3}}{\partial t}=\lambda_{3}\left(\frac{\partial^{2} T_{3}}{\partial r^{2}}+\frac{1}{r} \frac{\partial T_{3}}{\partial r}+\frac{\partial^{2} T_{3}}{\partial z^{2}}\right), t>0,0<r<r_{3}, z_{1}<z<z_{2} ; r_{2}<r<r_{3}, z_{2}<z<H ; \\
& c_{4} \rho_{4} \frac{\partial T_{4}}{\partial t}=\lambda_{4}\left(\frac{\partial^{2} T_{4}}{\partial r^{2}}+\frac{1}{r} \frac{\partial T_{4}}{\partial r}+\frac{\partial^{2} T_{4}}{\partial z^{2}}\right), t>0,0<r<L, 0<z<z_{1} ; r_{2}<r<r_{3}, z_{2}<z<H ;
\end{aligned}
$$

Where $\mathrm{r}$ - radial coordinate, $\mathrm{m} ; \mathrm{z}$ - axial coordinate, $\mathrm{m} ; \rho$ - density, $\mathrm{kg} / \mathrm{m}^{3} ; \mathrm{c}-$ specific heat capacity, $\mathrm{J} /\left(\mathrm{kg} \cdot{ }^{\circ} \mathrm{C}\right) ; \lambda$ - coefficient of heat conduction, $\mathrm{W} /\left(\mathrm{m} \cdot{ }^{\circ} \mathrm{C}\right)$; indexes: 1 thermocouple's junction, 2 - powder of an oxide of aluminum, 3 - a protective cover, 4 air.

The equivalent heat flux on outline borders is defined as the amount of a convective heat flux of $q_{c}$ and a heat flux caused by radiant heat exchange of $q_{r}$ :

$$
q_{\Sigma}=q_{c}+q_{r}
$$

Boundary conditions on inner and outline borders are given in the table 1.

\begin{tabular}{|c|c|c|c|}
\hline Edge conditions & $\begin{array}{c}\text { Decision area } \\
\text { boundary }\end{array}$ & Edge conditions & $\begin{array}{c}\text { Decision area } \\
\text { boundary }\end{array}$ \\
\hline $\begin{array}{l}T_{1}\left(r_{1}, z\right)=T_{2}\left(r_{1}, z\right) \\
-\left.\lambda_{1} \frac{\partial T_{1}}{\partial r}\right|_{r=r_{1}}=-\left.\lambda_{2} \frac{\partial T_{2}}{\partial r}\right|_{r=r_{1}}\end{array}$ & $\left(z_{3}<z<H\right)$ & $\begin{array}{l}T_{1}\left(r, z_{3}\right)=T_{2}\left(r, z_{3}\right) \\
-\left.\lambda_{1} \frac{\partial T_{1}}{\partial z}\right|_{z=z_{3}}=-\left.\lambda_{2} \frac{\partial T_{2}}{\partial z}\right|_{z=z_{3}}\end{array}$ & $\left(0<r<r_{1}\right)$ \\
\hline $\begin{array}{l}T_{2}\left(r_{2}, z\right)=T_{3}\left(r_{2}, z\right) ; \\
-\left.\lambda_{2} \frac{\partial T_{2}}{\partial r}\right|_{r=r_{2}}=-\left.\lambda_{3} \frac{\partial T_{3}}{\partial r}\right|_{r=r_{2}}\end{array}$ & $\left(z_{2}<z<H\right)$ & $\begin{array}{l}T_{2}\left(r, z_{2}\right)=T_{3}\left(r, z_{2}\right) \\
-\left.\lambda_{2} \frac{\partial T_{2}}{\partial z}\right|_{z=z_{2}}=-\left.\lambda_{3} \frac{\partial T_{3}}{\partial z}\right|_{z=z_{2}}\end{array}$ & $\left(0<r<r_{2}\right)$ \\
\hline $\begin{array}{l}T_{3}\left(r_{3}, z\right)=T_{4}\left(r_{3}, z\right) ; \\
-\left.\lambda_{3} \frac{\partial T_{3}}{\partial r}\right|_{r=r_{3}}=-\left.\lambda_{4} \frac{\partial T_{4}}{\partial r}\right|_{r=r_{3}}\end{array}$ & $\left(z_{1}<z<H\right)$ & $\begin{array}{l}T_{3}\left(r, z_{1}\right)=T_{4}\left(r, z_{1}\right) \\
-\left.\lambda_{3} \frac{\partial T_{3}}{\partial z}\right|_{z=z_{1}}=-\left.\lambda_{4} \frac{\partial T_{4}}{\partial z}\right|_{z=z_{1}}\end{array}$ & $\left(0<r<r_{3}\right)$ \\
\hline$\frac{\partial T}{\partial z}=0$ & $(z=H)$ & $\frac{\partial T}{\partial r}=0$ & $(r=0)$; \\
\hline$-\lambda_{4} \frac{\partial T_{4}}{\partial z}=q$ & $(z=0)$; & $-\lambda_{4} \frac{\partial T_{4}}{\partial r}=q$ & $(r=R)$ \\
\hline
\end{tabular}

Table 1. Boundary conditions of the task of heattransfer with the given external heat flux and boundary heat exchange.

The solution of the task is executed by method of finite differences on the basis of the four-dot implicit difference diagram [9]. The area of the solution of the task represents a grid $200 \times 200$ nodes with steps of $2,5 \cdot 10^{-2} \mathrm{~mm}$ on axial and radial coordinates, a step on $\mathrm{dt}$ time $=0,001 \mathrm{sec}[9]$.

\section{Results and discussion}

Simulation is executed taking into account heatphysical characteristics of elements of area of the solution of the task similar provided in operations $[4,5]$. 
Distributions of temperatures on a sensitive element of the thermocouple in case of temperature measurement $1000 \mathrm{~K}$ taking into account and without radiation heat exchange are shown in a figure 2.

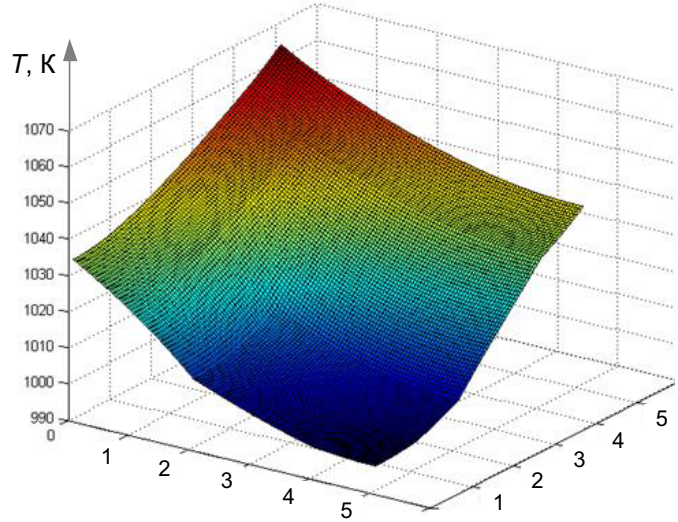

a)

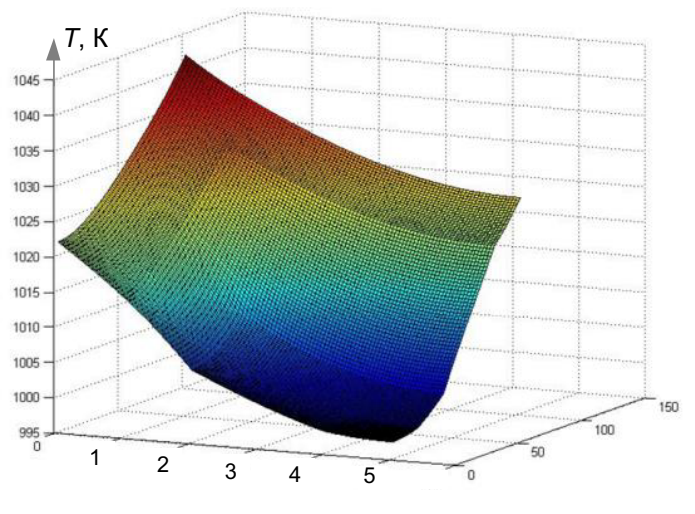

b)

Fig. 2. Dependences of necessary duration of heating up of the sensor without (1) and taking into account (2) influence of radiant heat exchange.

It is visible that in identical conditions of measurement up to the temperature of 1000 To intensity of heating up of a sensitive element of the sensor taking into account radiation heat exchange (fig. 2, b) above

The dependences of minimum necessary times of heating of the TEP sensitive element received taking into account only convective and equivalent heat exchange are given in a figure 3 .

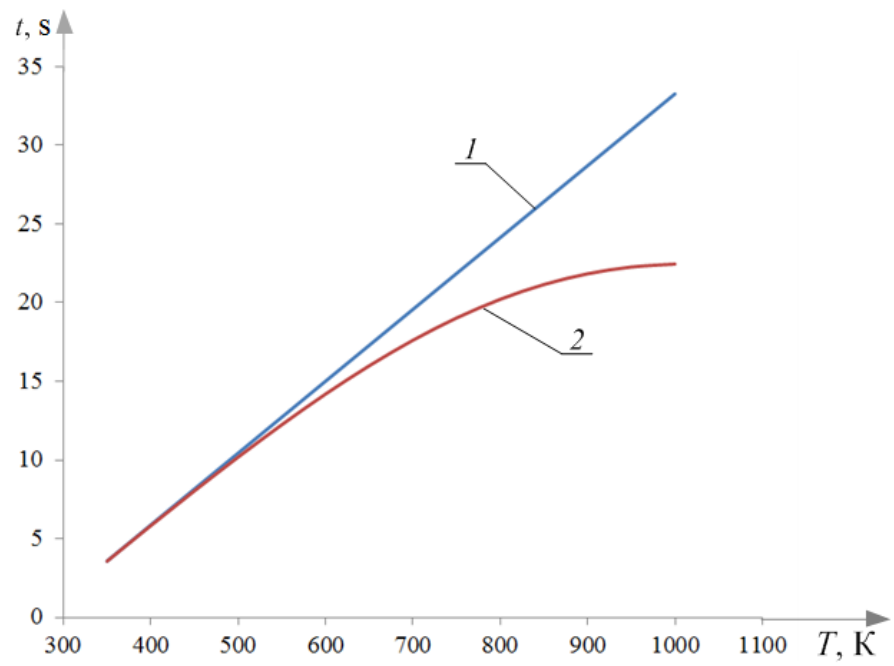

Fig. 3. Dependences of necessary duration of heating up of the sensor without (1) and taking into account (2) influence of radiant heat exchange.

It is visible that that influence of radiant heat exchange to $30 \%$ reduces the necessary duration of heating due to increase in the equivalent heat flux.

For an impact assessment of the free convection in liquid III layers (fig. 1, a) the equivalent coefficient of heat conduction was evaluated: 


$$
\lambda_{\ni}=\lambda_{\varkappa}\left[1+\frac{m\left(G r_{c} \cdot P r_{c}\right)^{n}}{G r_{c} \cdot P r_{c}+S}\right] .
$$

где $m, n, S$ - the coefficients determined by the geometrical sizes and the form of the gap filled with liquid; $\mathrm{Gr}$ - Grashof number, $\mathrm{Pr}$ - Prandtle number.

Then the relative deviation of the equivalent coefficient of heat conduction from coefficient of heat conduction of liquid is defined by expression:

$$
\delta \lambda=\frac{\lambda_{\ni}-\lambda_{\mathscr{H}}}{\lambda_{\ni}} \cdot 100 \%=\frac{\frac{m\left(G r_{c} \cdot P r_{c}\right)^{n}}{G r_{c} \cdot P r_{c}+S}}{1+\frac{m\left(G r_{c} \cdot P r_{c}\right)^{n}}{G r_{c} \cdot P r_{c}+S}} \cdot 100 \%=\frac{m\left(G r_{c} \cdot P r_{c}\right)^{n} \cdot 100 \%}{G r_{c} \cdot P r_{c}+S+m\left(G r_{c} \cdot P r_{c}\right)^{n}}=0,0021 \% .
$$

It is visible that the relative deviation of the equivalent coefficient of heat conduction taking into account influence of the free convection from coefficient of heat conduction of liquid isn't enough (less than 1\%) that allows to draw a conclusion that the free convection in liquids (fillers of protective sleeves) can be neglected.

\section{Conclusion}

The conducted researches showed that influence of radiation heat exchange exerts the considerable impact on process of heat transfer in a sensitive element of the thermocouple in case of measurement of temperatures higher than $700 \mathrm{~K}$, in particular, in case of temperature measurement $1000 \mathrm{~K}$ necessary time of heating up can be lowered to $30 \%$. It is set that influence of the free convection in layers of the liquid filling a protective sleeve has no significant effect on process of heat-transfer in system "the protective sleeve - buffer material - thermocouple".

\section{Acknowledgments}

This research was supported by the Russian Foundation for Basic Research (No. 14-0800057). The work at the field of modeling of heat and mass transfer processes near boundary "liquid-gas" was supported by the scientific schools grant NSH-7538-2016.8.

\section{References}

1. D. Matisková, M. Kotus, M. Balara, J. TEM 5, 60 (2016)

2. M. Ranusawud, P. Limsuwan, K. Vatcharanukul, T. Somthong, Key Engineering Materials 613, 133 (2014)

3. G. Bucur, O. Cangea, Petroleum - Gas University of Ploiesti Bulletin, Technical Series 66, 1 (2014)

4. Y.K. Atroshenko and A.A. Bychkova, MATEC Web Conf. 23, 01006 (2015)

5. Y.K. Atroshenko and A.V. Abramova, EPJ Web Conf. 110, 01071 (2016)

6. M.A. Taymarov, Yu.V. Lavirko, E.E. Belyaeva, Proceedings of the higher educational institutions. Energy Sector Problems 7, 69 (2015)

7. A.N. Makarov, Power Station 3, 19 (2015)

8. GOST 6651-2009 Thermal resistance of platinum, copper and nickel. General technical requirements and test methods, Moscow (2009) [in Russian]

9. A.A. Samarskii, The Theory of Difference Schemes (Marcel Dekker, Inc., New York, 2001) 